\title{
Finding Optimal Feed Location of a Microstrip Patch Antenna using HFSS
}

\author{
TVS Divakar ${ }^{1}$, Dhruba C. Panda ${ }^{2}$ \\ Centurion University of Technology and Management ${ }^{1}$ \\ Dept. of Electronic Science, Berhampur University, Odisha, India ${ }^{2}$
}

\begin{abstract}
Microstrip patch antennas represent one family of compact antennas that offer a conformal nature and the capability of ready integration with communication system's printed circuitry. In this paper, a microst rip antenna has been designed at $1.9 \mathrm{GHz}$ using ANSOFT-HFSS. By varying the feed point, good value of return loss is obtained and optimum position of feed point and the bandwidth are also determined.
\end{abstract}

Keywords: ANSOFT-HFSS, microstrip, EM radiation

\section{INTRODUCTION}

Microstrip antennas are used in high performance aircraft, spacecraft, satellite and missile application, where size, weight, cost, performance, ease of installation and aerodynamic profile are constraints [1]. Presently there are many government and commercial applications of microstrip antennas such as mobile radio and wireless communications. Microstrip antennas however have limitations in terms of bandwidth and efficiency, all imposed by the presence of dielectric substrate? A modified rectangular patch antenna with an air gap in between the two substrate layers of patch is analyzed to achieve compact size, light weight and wide band operation [2].

There are many configurations that can be used to feed microstrip antennas. The four most popular are microstrip line, coaxial probe, aperture coupling and proximity coupling [3]. Coaxial feed method is widely used because of its simplicity in fabrication and matching and it has low spurious radiation. Matching may be achieved by properly selecting the location of the feed may also affect the radiation characteristics. In view of this, an attempt has been made to determine the optimum feed position of microstrip antenna designed at $1.9 \mathrm{GHz}$. Optimum feed position can be obtained by finding the Return loss [4]. Because Return loss is convenient way to characterize the input and output of signal sources. In other words, when the load is mismatched, not all the available power from generator is delivered to the load. This loss is termed as return loss and is expressed in $\mathrm{dB}$.

There are many methods of analysis for microstrip antennas. Most popular models are Transmission Line Model (TLM), cavity and full wave. In this paper, a compact rectangular microstrip patch antenna for use in cellular phones is designed using HFSS.

\section{Design Procedure}

The essential parameters for the design are resonant For a given resonance frequency $f_{o}$ the effective length is frequency $\mathrm{f}_{0}=1.9 \mathrm{GHz}$, dielectric constant of the material is given by $\varepsilon_{\mathrm{r}}=11.5$ and height of the substrate is $1.3 \mathrm{~mm}$.

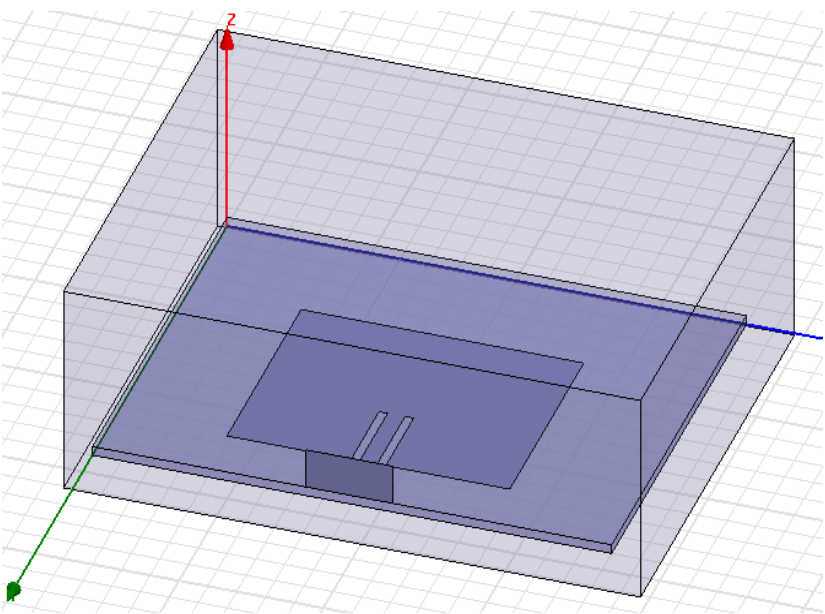

Fig 1. Top view of Microstrip Patch Antenna in HFSS.

For an efficient radiator, practical width that leads to good radiation efficiencies is

$$
\begin{aligned}
& W=\frac{1}{2 f_{r} \sqrt{\mu_{0} \epsilon_{0}}} \sqrt{\frac{2}{\epsilon_{r}+1}}=\frac{v_{0}}{2 f_{r}} \sqrt{\frac{2}{\epsilon_{r}+1}} \\
& \varepsilon_{\text {reff }}=\frac{\varepsilon_{r}+1}{2}+\frac{\varepsilon_{r}-1}{2}\left[1+\mid 12 \frac{h}{W}\right]^{-\frac{1}{2}}
\end{aligned}
$$




$$
L_{e f f}=\frac{c}{2 f_{o} \sqrt{\varepsilon_{r e f f}}}
$$

The dimensions of the patch along its length will be extended because of fringing fields on each end by a distance $\Delta \mathrm{L}$, which is given empirically by Hammerstad as:-

$$
\begin{aligned}
& \Delta L=0.124 h \frac{E_{\text {xeff }}+0.3}{E_{\text {eff }}-0.258}\left[\frac{\frac{W}{h}+0.264}{\frac{W}{h}+0.8}\right]-\cdots \\
& L=\mathbb{L}_{\text {aff }}-2 \Delta L \text {--------5 }
\end{aligned}
$$

Using equations (1) to (5), we can readily calculate $\mathrm{W}=30.8 \mathrm{~mm}, \quad \varepsilon_{\text {reff }}=10.6, \quad \mathrm{~L}_{\text {eff }}=23 \mathrm{~mm}, \Delta \mathrm{L}=0.64 \mathrm{~mm} \quad$ and $\mathrm{L}=21.8 \mathrm{~mm}$.

The feed point must be located at that point on the patch, where the input impedance is $50 \Omega$ for the resonant frequency. So, for different locations of the feed point, the return loss (R.L) is compared and that feed point is selected where the R.L is most negative.

\section{Simulation Setup ANd Results}

The software used to model and simulate the microstrip patch antenna is HFSS. It enables us to model the structures of arbitrary shape using wires and plates as basic building blocks. The basic steps when using the 3D EM solver are defining the problem, editing and checking the input data, saving the project and running the analysis, listing and plotting the computed results.

The designed microstrip antenna which is modeled in HFSS is shown in Fig. 1. For simplicity, the length and width of patch and ground plane have been rounded off to nearest decimal value. Figs. 2-3 shows the plot of return loss for different feeding positions. The coaxial probe feed is designed to have a radius of $0.5 \mathrm{~mm}$. A frequency range of $1.7-2.1 \mathrm{GHz}$ is selected and 9 frequency points are selected over this range to obtain accurate results.

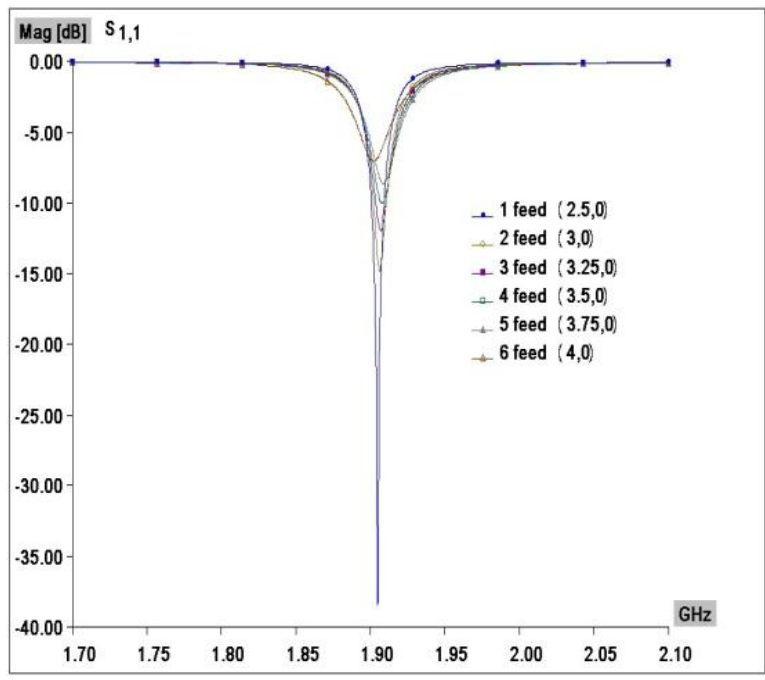

Fig. 2. Return loss for feed located at different points.

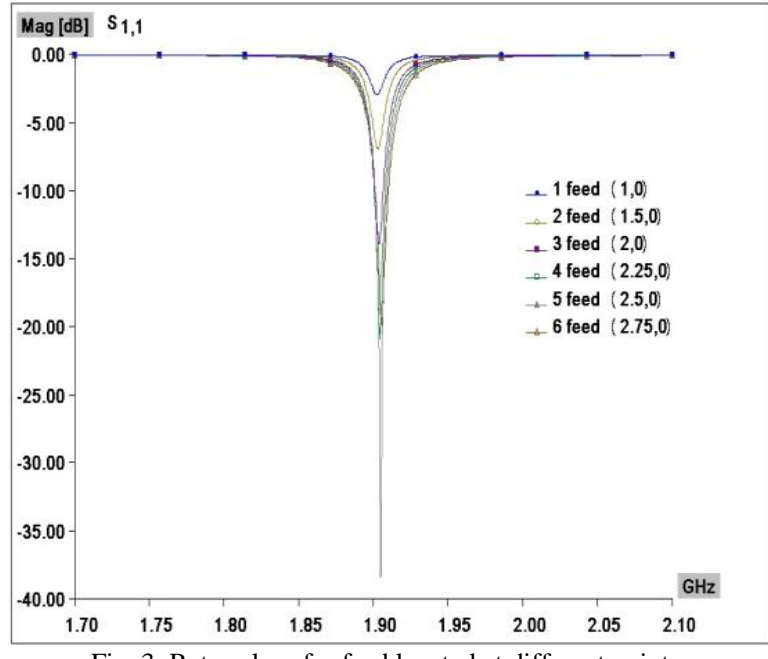

Fig. 3. Return loss for feed located at different points.

The centre frequency is selected as the one at which the return loss is minimum. Bandwidth can be calculated from the return loss plot. The bandwidth of the antenna is said to be those range of frequencies over which the return loss is greater than $-9 \mathrm{~dB}$ [7] the optimum feed location is found to be at $(2.5,0)$ with a return loss of $-38.28 \mathrm{~dB}$ as shown in Fig. 4. The bandwidth obtained is $10 \mathrm{MHz}$ and a center frequency of $1.91 \mathrm{GHz}$ which is very close to the desired design frequency $1.9 \mathrm{GHz}$. Table 1 shows the full result set at different feed locations the values of return loss and bandwidth.

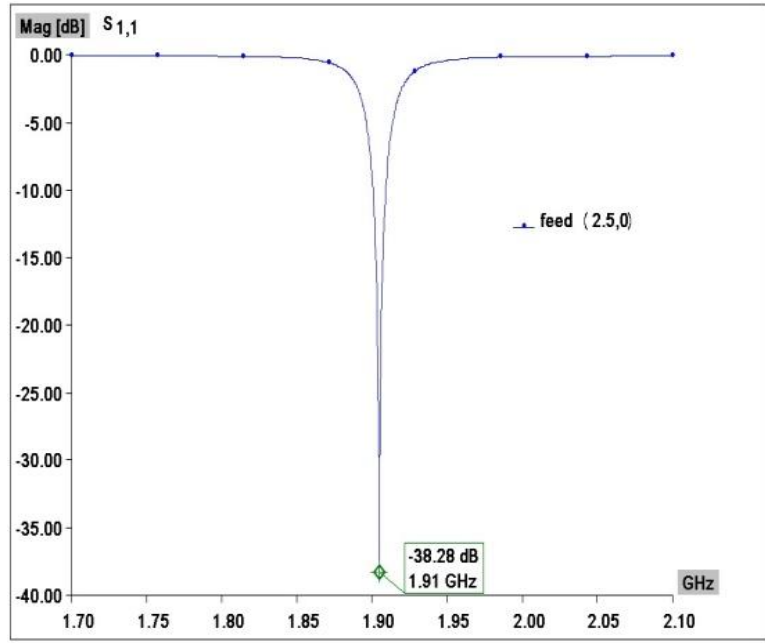

Fig. 4. Return Loss at feed $(2.5,0)$

\begin{tabular}{|c|c|c|c|c|}
\hline No. & $\begin{array}{c}\text { Feed } \\
\text { Location } \\
\left(\mathbf{X}_{f}, \mathbf{Y}_{f}\right) \\
(\mathbf{m m})\end{array}$ & $\begin{array}{c}\text { Center } \\
\text { Frequency } \\
(\mathbf{G H z})\end{array}$ & $\begin{array}{c}\text { Return } \\
\text { Loss } \\
(\mathbf{R L}) \\
(\mathbf{d B})\end{array}$ & $\begin{array}{c}\text { Bandwidth } \\
(\mathbf{R L}>\mathbf{- 9} \mathbf{~ d B}) \\
(\mathbf{M H z})\end{array}$ \\
\hline 1. & $(1,0)$ & 1.90 & -2.92 & -- \\
\hline 2. & $(1.5,0)$ & 1.90 & -6.80 & -- \\
\hline 3. & $(2,0)$ & 1.90 & -13.87 & 6 \\
\hline 4. & $(2.25,0)$ & 1.90 & -20.80 & 8 \\
\hline 5. & $(2.50,0)$ & 1.91 & -38.28 & 10 \\
\hline 6. & $(2.75,0)$ & 1.91 & -19.68 & 9 \\
\hline 7. & $(3,0)$ & 1.91 & -14.54 & 9 \\
\hline 8. & $(3.25,0)$ & 1.90 & -11.80 & 8 \\
\hline 9. & $(3.50,0)$ & 1.90 & -9.84 & 4 \\
\hline 10. & $(3.75,0)$ & 1.90 & -8.47 & -- \\
\hline 11. & $(4,0)$ & 1.90 & -6.92 & -- \\
\hline
\end{tabular}

Table .1 Effect of feed location on center frequency, return loss and bandwidth. 
Since a microstrip patch antenna radiates normal to its patch surface, elevation pattern for $\varphi=0$ and $\varphi=90^{\circ}$ would be important [8]. Fig. 5 represents rectangular plot overlaid when $\varphi=0$ and $\varphi=90^{\circ}$. Fig. 6 represents polar plot overlaid when $\varphi=0$ and $\varphi=90^{\circ}$. Fig. 7 shows 3D pattern of designed microstrip antenna at $1.9 \mathrm{GHz}$.

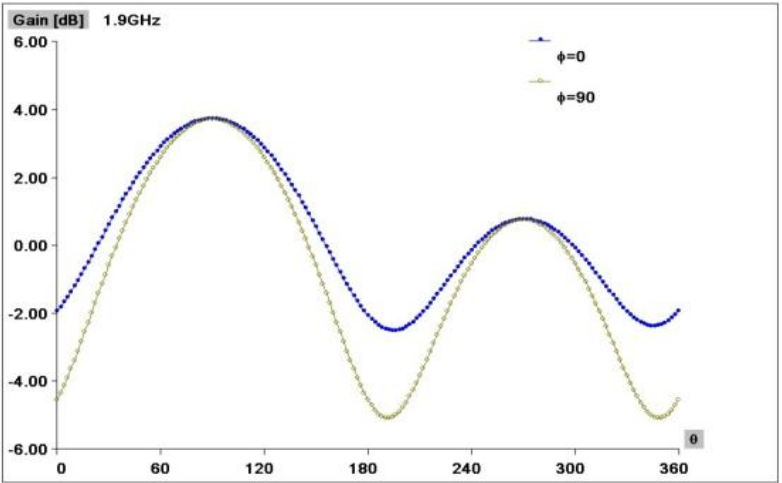

Fig. 5. Rectangular Plot for $\varphi=0$ and $\varphi=90^{\circ}$.

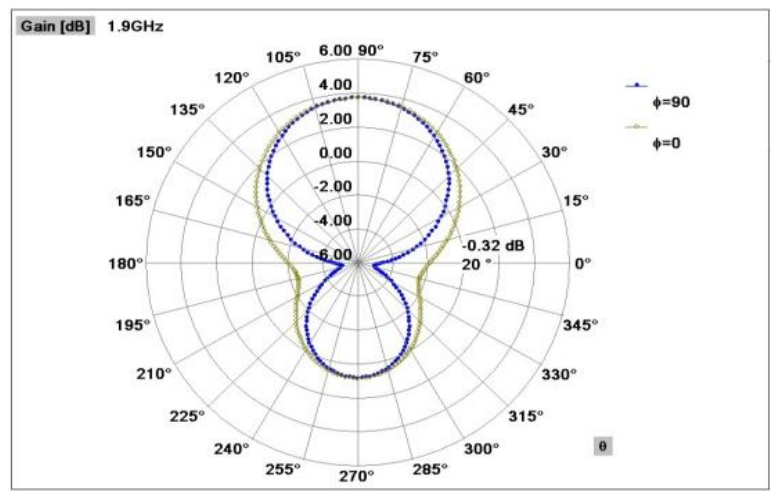

Fig. 6. Polar Plot for $\varphi=0$ and $\varphi=90^{0}$.

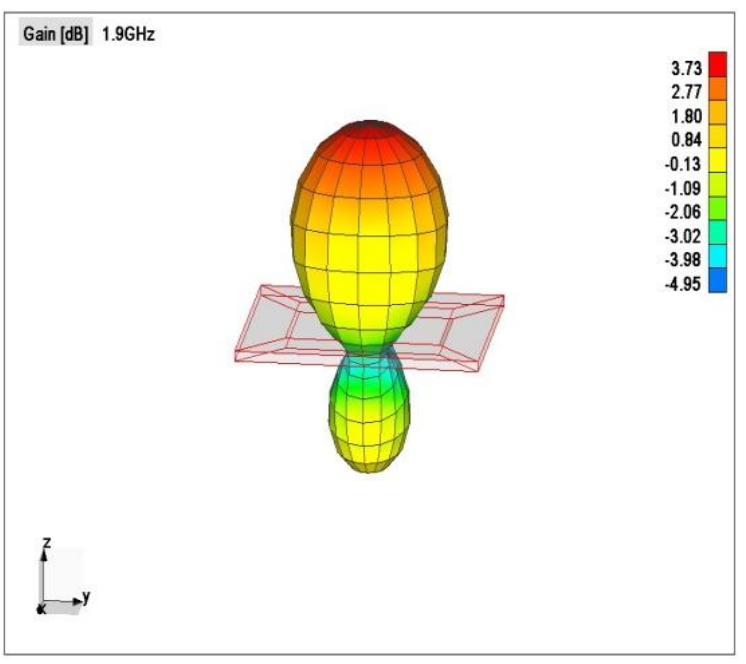

Fig. 7. 3D Radiation pattern of designed microstrip antenna.

\section{CONCLuSions}

A Rectangular microstrip patch antenna has been successfully designed at $1.9 \mathrm{GHz}$. It is observed from the table as the feed point location is moved away from the centre of the patch, the centre frequency starts to decrease slightly. Maximum return loss of $-38.28 \mathrm{~dB}$ is obtained at feed location $(2.5,0)$. Bandwidth calculated is $10 \mathrm{MHz}$. Maximum gain is obtained in the broad side direction and this is measured as $3.73 \mathrm{~dB}$. The back lobe radiation is sufficiently small and is measured as $-0.13 \mathrm{~dB}$. It is an advantage for using this antenna in a cellular phone, since it reduces the amount of EM radiation which travels towards the users head.

\section{REFERENCES}

1. S.R. Schmidt and R.G. Launsby, Understanding Industrial Designed Experiments, Colorado Springs, CO: Air Force Academy, pp. 3.1-3.50, 1992

2. Vijay Sharma, Brajrajsharma, V.K. Saxeena, K.B. Sharma, "Modified Rectangular Patch Antenna with Air Gap for Improved Bandwidth", Proc. of Int. Conf. on Microwave, pg. 227-229, 2008.

3. Constantain. A. Balanis, Antenna Theory Analysis and Design, III Edn., Wiley-Interscience. A John Wiley \& Sons Inc. Publicaiton.

4. David M. Pozar, Microwave Engineering, John Wiley and sons, 1998.

5. Z.I. Dafalla, W.T.Y. Kuan, A.M. Abdel Rahman, S.C. Shudakar, Design of a Rectangular Microstrip Patch Antenna at $1 \mathrm{GHz}$, IEE Proc. on RF and Microwave Conf.,pg. 145-149, 2004.

6. I. Sarkari, P.P. Sarkar, S.K. Chowdhury, A New Compact Printed Antenna for Mobile Communication, IEEE Proc. on Antenna and Propagation, pg. 109-112, 2009.

7. Bonny Banerjee "A Self-Organizing Auto-Associative Network for the Generalized Physical Design of Microstrip Patches" IEEE TRANSACTIONS ON ANTENNA AND PROPAGATION p-p 1301-1306 VOL. 51, NO. 6, JUNE 2003

8. B.M.Kolundzija, J.S.Ognjanovic, T.K.Sarkar and R.F.Harrington, WIPL:Electro magnetic modeling of composite wire and plate structures-software and user's manual, Norwood:Artech house, 1995 